\title{
A prospective study on association of primary infertility and fibroid uterus
}

\author{
Shikha Aggarwal', Maryam Rahim¹, Tarini Singh², Debkalyan Maji ${ }^{3 *}$
}

\begin{abstract}
${ }^{1}$ Department of Obstetrics and Gynaecology, Altnagelvin Hospital, Northern Ireland, UK
${ }^{2}$ Department of Obstetrics and Gynaecology, SMGS Govt. Medical College, Jammu, Jammu and Kashmir, India

${ }^{3}$ Department of Obstetrics and Gynaecology, Military Hospital, Gwalior, Madhya Pradesh, India
\end{abstract}

Received: 01 May 2021

Accepted: 24 May 2021

*Correspondence:

Dr. Debkalyan Maji,

E-mail: dr.debkalyan@gmail.com

Copyright: (c) the author(s), publisher and licensee Medip Academy. This is an open-access article distributed under the terms of the Creative Commons Attribution Non-Commercial License, which permits unrestricted non-commercial use, distribution, and reproduction in any medium, provided the original work is properly cited.

\begin{abstract}
Background: Implication of fibroid uterus on infertility is still debateable. Co-existence of infertility and fibroid uterus has been observed many times in clinical practice. This study is conducted to ascertain the frequency of primary infertility in women suffering from fibroid.

Methods: A prospective observational study was conducted at AL Qassmi Women's and Children's Hospital, Sharjah - UAE over a period of six months from January 2018 to June 2018. Total 100 patients were participated in the study. All data were collected and analysed using SPPS ver 20 software.

Results: During the study period, a total of one hundred women presented with fibroid uterus were observed. All the cases were within the reproductive age group ranging from 20-43 years of age. $40 \%$ for cases were between $20-27$ years, $49 \%$ cases were between $28-35$ years and $11 \%$ belonged to $36-43$ years of age. Considering the symptoms, infertility was $14 \%$. According to the number of fibroids, in $22 \%$ of cases, there were multiple fibroids. The single uterine fibroid was seen in $78 \%$ of cases.

Conclusions: Fibroid is relatively common in patients of reproductive age and was associated with infertility in $14 \%$ of cases.
\end{abstract}

Keywords: Fibroid uterus, Primary infertility, Leiomyoma uterus

\section{INTRODUCTION}

Leiomyomas are benign tumours of smooth muscles occurring mainly in the uterus. Uterine cavity leiomyomas are indeed the most common pathological growth in the female genital tract affecting about $40 \%$ of the female population. ${ }^{1}$ Leiomyomas may remain symptomless in a small group of patients, but majority of affected people generally presents with morbid symptoms. ${ }^{2}$ The common symptom with which patients with fibroid uterus come to the OPD (outpatient department) is menorrhagia but a significant number of patients suffer from primary infertility too. ${ }^{3}$ Among the general effects, sign and symptoms of anaemia are probably the most common apart from weakness, breathlessness or both. Leiomyoma's may present with pressure symptoms such as the sensation of weight in the pelvis, oedema and varicosities of legs and bladder irritability. Abortion, abnormal placentation, mal presentation, obstructed labours, preterm labour and labour dystocia are the seen in gravid patient with fibroid uterus.

Other factors such as parity, age, social and genetic factors have also been postulated but never established with certainty. Infertility is commonly associated with myomas. The majority of patients are either nulliparous or of low parity. The association between fibroid uterus and primary infertility is intriguing principally because of each support and augments the other in a vicious cycle. Approximately 
$50 \%$ of the women with infertility and myomas become pregnant after myomectomy. ${ }^{4}$

Indeed, leiomyomas represent an increasing medical problem in women attempting to conceive at a more advanced age, when the rate of development of these lesions is also increased. Uterine fibroids have been reported in $27 \%$ of infertile women. It has observed in studies that approx. $50 \%$ of women with unexplained infertility become pregnant after myomectomy., The age at which a first pregnancy occurs, is increasing from the mid-twenties to thirties/forties. This shifted age of first child birth and increased leiomyoma frequency among these age group, are the background to conduct this study. The aim of the present study is to ascertain the frequency of primary infertility in women suffering with fibroid uterus.

\section{METHODS}

It was a prospective observational study conducted at the department of obstetrics and gynaecology, AL Qassmi Women's and Children's Hospital, Sharjah - UAE over a period of six months from January 2018 to June 2018.. The study was approved by institutional ethical committee. Informed written consent was taken from all participant of study population. All patients in this study were included based on a detailed history, clinical examination investigations through the outdoor patient department. Detailed questions including age, parity, chief complaints, history of a medical disorder and surgery were taken. Each patient was examined thoroughly after obtaining complete and detail history. The fibroid was confirmed by ultrasonography. All analysis was done by SPSS version 20 and appropriate statistical tests were used for analysis.

\section{Inclusion criteria}

All women with fibroid uterus (symptomatic/ asymptomatic) attending infertility OPD for primary infertility were included in the study.

\section{Exclusion criteria}

Women with fibroid uterus attending infertility OPD for secondary infertility were excluded from the study.

\section{RESULTS}

Total 100 patients were participated in study and fulfilled the inclusion and exclusion criteria. All the women were counselled regarding the aim and objective of the study and informed consent were taken. All the cases were within the age group ranging from 20 years to 43 years of age. $40 \%$ were between $20-27$ years, $49 \%$ were between 28-35 years, and $11 \%$ were $36-43$ years of age group. The mean age was $33 \pm 4.5$ years (Table 1 ).

Considering the symptoms, primary infertility was associated with $14 \%$ of cases. Asymptomatic, menstrual abnormality and lower abdominal pain were noted in $24 \%$, $52 \%$ and $6 \%$ cases respectively. Different type of pressure symptoms like frequency of micturition, chronic constipation and varicosity was $4 \%$ (Table 2 ). According to the number of leiomyomas, in $22 \%$ of cases, there were multiple leiomyomas. Single uterine leiomyoma was seen in $78 \%$ of cases (Table 3).

Table 1: Age distribution of study population.

\begin{tabular}{|lll|}
\hline Age (years) & $\begin{array}{l}\text { Number, } \\
(\mathbf{n = 1 0 0})\end{array}$ & $\begin{array}{l}\text { Percentage } \\
(\%)\end{array}$ \\
\hline $\mathbf{2 0 - 2 7}$ & 40 & 40 \\
\hline $\mathbf{2 8 - 3 5}$ & 49 & 49 \\
\hline $\mathbf{3 6 - 4 3}$ & 11 & 11 \\
\hline
\end{tabular}

Table 2: Presenting symptoms.

\begin{tabular}{|lll|}
\hline Symptoms & $\begin{array}{l}\text { Number, } \\
(\mathbf{n = 1 0 0 )}\end{array}$ & $\begin{array}{l}\text { Percentage } \\
(\%)\end{array}$ \\
\hline Primary infertility & 14 & 14 \\
\hline $\begin{array}{l}\text { Menstrual } \\
\text { abnormalities }\end{array}$ & 52 & 52 \\
\hline Pain & 6 & 6 \\
\hline Asymptomatic & 24 & 24 \\
\hline $\begin{array}{l}\text { Pressure } \\
\text { symptoms } \\
\text { (frequency etc.) }\end{array}$ & 4 & 4 \\
\hline
\end{tabular}

Table 3: Number of fibroids among study population.

\begin{tabular}{|llc|}
$\begin{array}{l}\text { Numbers of } \\
\text { fibroids }\end{array}$ & $\begin{array}{l}\text { Number, } \\
(\mathbf{n = 1 0 0})\end{array}$ & $\begin{array}{c}\text { Percentage } \\
(\%)\end{array}$ \\
\hline Solitary & 78 & 78 \\
\hline Multiple & 22 & 22 \\
\hline
\end{tabular}

\section{DISCUSSION}

The exact aetiology of leiomyoma uteri is entirely unknown. It has been seen through that the growth of uterine fibroids is clearly dependent upon ovarian hormones since fibroids rarely occur before puberty and after menopause and an increase in size may actually recede after menopause. ${ }^{5}$ A Leiomyoma is relatively common in patients of reproductive age. Approximately $50 \%$ of women with infertility and myomas become pregnant after myomectomy. Uterine leiomyoma constitutes a major public health problem to the community in term of outpatient attendance and hospital cost for surgery. ${ }^{6}$ The actual cause and effect relationship between fibroids and primary infertility has not been established but it is clear that fibroids or leiomyomas in the uterus interfere with the implantation of the zygote in the uterus. ${ }^{7}$

The relationship of myomas and infertility remains a subject of debate. Leiomyomas are associated with infertility, the causal relationship in this regard appearing to be more evident for submucosal myomas. Myomas may also be associated with implantation failure or gestation 
discontinuation due to focal endometrial vascular disturbance, endometrial inflammation, secretion of vasoactive substance or an enhanced endometrial androgen environment. ${ }^{8}$

Leiomyomas of the uterus are the most common solid pelvic tumours in women and are present in 20 to $25 \%$ of women aged $>35$ years. ${ }^{9}$ Indeed, Leiomyomas represent an increasing medical problem in women attempting to conceive at a more advanced age, when the rate of development of these lesions is also increased. Uterine fibroids have been reported in $27 \%$ of infertile women, and $50 \%$ of women with unexplained infertility have seen the presence of leiomyomas. $^{2}$

The mean age of the study population was $33 \pm 4.5$ years and majority of study population belonged to age group of 28-36 years. Akhter et al in their study reported the mean age of study population was $26.5 \pm 5.35$ years which was less than the finding of our studies. ${ }^{10}$ However, the mean age of study population in our study was relatively higher which was probably due to socioeconomic factor and recent change in trend of becoming first time pregnant in early thirties. In this study frequency of primary infertility in uterine leiomyomas was $14 \%$. Although the aetiology is unknown but certain factors were determined which predispose to uterine leiomyoma; like the family history, chronic pelvic infection and ovarian cyst with anovulatory cycle. The association of primary infertility and uterine fibroid was $5-10 \%$ as reported by the study conducted Carranza-Mamane et al. ${ }^{11}$ Earlier study by Buttram et al, Verkauf et al reported the association of primary infertility and myomas ranged from $1-2.4 \% .{ }^{8,12}$ In this study, we have found that $22 \%$ cases have multiple fibroids and $78 \%$ have a solitary fibroid. The results of my study were comparable to a study carried out by Davis et al. ${ }^{13}$

\section{CONCLUSION}

Leiomyoma is relatively common in patients of reproductive age and was exclusively associated with infertility in $14 \%$ of cases. The role of uterine fibroids remains controversial but seems to suggest that the presence of myomas decrease the pregnancy rates. Therefore, further trials with larger patients, samples are needed to verify the relation of fibroids and primary infertility.

\section{ACKNOWLEDGMENTS}

Authors would like to thank to all patient consented and participated in this study.

Funding: No funding sources

Conflict of interest: None declared

Ethical approval: The study was approved by the Institutional Ethics Committee

\section{REFERENCES}

1. Sutton CJ. Treatment of large uterine fibroids. Bri J obstetr gynaecol. 1996;103(6):494-6.

2. Lowe GD. Benign tumor of uterus. In: Edmond KD. Dew Hurst text book of gynecology for postgraduates. $6^{\text {th }}$ ed. London: Blackwell Science. 2007;552-4.

3. Lethaby A, Vollenhoven B. Fibroids (uterine myomatosis, leiomyomas). BMJ Clin Evid. 2015;2015.

4. Christopher P. Female genital tract. In: Ramzi S, Kumar V, Robbins S. Robbins Pathologic basis of disease, $7^{\text {th }}$ ed. New York, W.B Saunders. 2004;1059.

5. Bhatia N. Tumours of the corpus uteri. In: Bhatla N, Jeff Coates R. Jeff Coate's principles of gynecology $5^{\text {th }}$ ed. London: Arnold. 2001;471-80.

6. Miller NF, Ludovici PP. On the origin and development of uterine fibroids. Am J Obstetr Gynecol. 1955;70(4):720-40.

7. Adrian M. Surgical Anatomy. In: Shaw WR, Soutter L. Shaw's Churchill Livingstone. 2003;23-35.

8. Buttram VC Jr, Reiter RC. Uterine leiomyomata: etiology, symptomatology, and management. Fertility Sterility. 1981;36(4):433-45.

9. Donnez J, Jadoul P. What are the implications of myomas on fertility?: A need for a debate? Human Reprod. 2002;17(6):1424-30.

10. Akhter S, Alam H, Khanam NN, Zabin F. Characteristics of infertile couples. Mymensingh Med J. 2011;20(1):121-7.

11. Carranza-Mamane B, Havelock J, Hemmings R. The management of uterine fibroids in women with otherwise unexplained infertility. J Obstetr Gynaecol Canada. 2015;37(3):277-85.

12. Verkauf BS. Myomectomy for fertility enhancement and preservation. Fertility sterility. 1992;58(1):1-15.

13. Davis JL, Ray-Mazumder S, Hobel CJ, Baley K, Sassoon D. Uterine leiomyomas in pregnancy: a prospective study. Obstetr Gynecol. 1990;75(1):41-4.

Cite this article as: Aggarwal S, Rahim M, Singh T, Maji D. A prospective study on association of primary infertility and fibroid uterus. Int J Reprod Contracept Obstet Gynecol 2021;10:2246-8. 